Journal of Physical Education and Sport Studies Beden Eğitimi ve Spor Araştırmaları Dergisi

\title{
Effects of Anthropometry on Volleyball Serve Performance
}

\section{Antropometrik Özelliklerin Voleybolda Servis Performansına Etkisinin İncelenmesi}

\author{
Yetkin Utku Kamuk ${ }^{1}$ \\ Faculty of Sport Sciences, Hitit University, Çorum, Turkey
}

\section{Fatih Şenduran}

National Defense University Land Forces NCO Vocational HS, Balıkesir, Turkey

\section{Zafer Doğru, Samet Aktaş \& Fatma Tanırgan}

Faculty of Sport Sciences, Hitit University, Çorum, Turkey

\begin{abstract}
The purpose of this study is to examine the effects of anthropometry on volleyball serve performance. The researchers recorded serve performances of the volleyball players that participated at the Universities Volleyball League organized by the Turkish University Sports Federation. The Volleyball Serve Scouting Sheet developed by the researchers was used to collect data. The area that the ball was served to, or the type of error (ace, net, out) were recorded on the sheet. Personal information of the athletes who volunteered to participate in the study was collected; height, raised arm height, and body weight were measured. The coefficient of variation and Q-Q plot test were used to test the normal distribution of the data. The significance level was set as $p<0.05$. Independent samples t-test was used for the statistical analysis. As a result, it was observed that the height and raised arm height of the male volleyball players had an effect on the ability to serve aces $(p<0.05)$.
\end{abstract}

Keywords: Raised arm height, sports, anthropometric.

\footnotetext{
${ }^{1}$ Corresponding author: Yetkin Utku Kamuk (ORCID: 0000-0001-5976-7503)

Hitit Üniversitesi, Spor Bilimleri Fakültesi, Kuzey Kampüsü Çevre Yolu Bulvarı 19030 Çorum, Turkey yetkinkamuk@hitit.edu.tr Fatih Şenduran (ORCID: 0000-0002-9463-7963)

Zafer Doğru (ORCID: 0000-0002-8902-0301)

Samet Aktaş (ORCID: 0000-0003-2350-9144)

Fatma Tanırgan (ORCID: 0000-0001-9658-3279)
} 


\section{$\ddot{\mathbf{O z}}$}

Bu çalışmanın amacl, voleybol oyuncularının antropometrik özelliklerinin servis performanslarına etkisini incelenmesidir. Bu amaçla, Türkiye Üniversite Sporları Federasyonu tarafindan gerçekleştirilen Ünilig Voleybol Müsabakalarına katılan bazı takımların müsabakaları izlenmiş ve oyuncuların servis performanslarının değerlendirilmesi için, araştırmacılar tarafindan geliştirilen servis performansı gözlem formu kullanılarak, müsabakalarda kullanılan servislerin, hangi bölgeye atıldı̆̆ ya da servisin doğrudan sayı ile sonuçlanıp sonuçlanmadığ kaydedilmiştir. Çalışmaya katılmayı kabul eden sporcuların kişisel bilgileri toplanmış; boy uzunluğu, erişme yüksekliği ve vücut ağırlğ̆ ölçümleri yapılmıştır. Verilerin normal dağıllma uygunluğunun test edilmesi için varyasyon katsaylsı ve Q-Q plot testi kullanılmış ve tüm istatistiklerde anlamlllk düzeyi 0,05 olarak kabul edilmişstir. Verilerin analizi için bağımsız örneklem t testi kullanılmıştır. Araştırma sonuçlarına göre, erkek voleybolcuların boy uzunluğu ve erişsme yüksekliği değerlerinin, servis atışında doğrudan sayı alma becerisi üzerinde etkili olduğu $(p<0,05)$ görülmüsțtür.

Anahtar kelimeler: Erişme yüksekliği, spor, antropometri.

\section{Giriş}

Günümüzde yaklaşık 100 yıllık bir geçmişe sahip olan voleybol sporu; kuvvete, hareketliliğe, esnekliğe ve dayanıklılığa gereksinim duyulan, değişik sportif becerileri içeren ve süreye bağlı olmayan bir takım oyunudur (Bayraktar \& Sunay, 2007; Çon, Akyol, Tural, \& Taşmektepligil, 2012). Tüm branşlarda olduğu gibi, voleybol sporunda da temel beceriler yer almakla birlikte, servis atışı, müsabaka başarısını etkileyen unsurların önde gelenlerinden biridir (Kamuk, 2017). Voleybol sporunda oyunun servis atışı ile başlaması gerektiğinden, her sayının başlangıcında kullanılan servis atışı, etkili bir servis tekniğine sahip oyuncular için avantaj olmaktadır. Böylelikle servis atışında doğrudan sayı kazanılabilmekte ya da rakibin etkili hücum yapma şansı azaltılabilmektedir. Bu durum, voleybol oyununda servis atışının öneminin artmasına neden olmuştur (Dinçer, 2016; İlhan, 2009).

Voleybolda, takımın başarısının belirleyicilerinden bir tanesi olarak kabul edilen servis atışı (Pena, RodriguezGuerra, Busca, \& Serra, 2013; Silva, Lacerda, \& Joao, 2014), oyuncunun teknik becerisi ve tecrübesinden etkilenmekle birlikte, rakibin sahadaki yerleşimi de servis performansını etkilemektedir (Paulo, Zaal., Fonseca, \& Araujo, 2016). Servis atıldığı noktanın bir müsabakayı kazanmayı ya da kaybetmeyi belirleyen önemli faktörlerden biri olduğu ortaya konmuştur (Patsiaouras Moustakidis, Charitonidis, \& Kokaridas, 2011). İyi bir şekilde kullanılan servis, rakip takımın hücum ve savunmaya yönelik stratejilerini bozma açısından önemli yere sahiptir. İyi bir servis, etkili bir hücum olarak düşünülebilir (İlhan, 2009).

Voleybol branşı, sporcuların fiziksel uygunluk düzeylerinin iyi olmasının ve sporcuların belirgin antropometrik özelliklere sahip olmalarının gerekli olduğu bir spor dalıdır (Göral, Saygın, Karacabey, \& Gelen, 2009) çünkü oyunun doğasında, sporcuların aşmaları gereken bir engel bulunmakta ve bu da antropometrik özelliklerin başarıdaki payını arttırmaktadır (Palao, Manzanares, \& Valades, 2014). Teknik ve taktik becerilerin yanı sıra antropometrik özelliklerin voleybol branşında başarıyı etkileyen önemli faktörler olduğu (Şimşek, Tuncel, Ertan, \& Göktepe, 2004) ve servis ile antropometrik özelliklerin anlamlı bir korelasyona sahip olduğu gösterilmiştir (Stamm vd., 2003). Voleybolcuların somatotipinin ektomorfik olması beklenmektedir (Pastuszak, Busko, \& Kalka, 2016). Ektomorf sporcular küçük kemiklere ve ince kaslara, düşük ve dar omuzlara, uzun kollara ve bacaklara, düşük kas oranına sahiptir (Kürkçü, Hazar, \& Özdağ, 2009). Kolların ve bacakların uzun olması voleybolda bir avantaj unsuru olarak görülmektedir (Sunay vd., 2003).

Vücut yapısının voleybola özel temel beceriler üzerindeki etkisini inceleyen birçok çalışma var olmakla birlikte, sadece oyunu başlatmaktan daha fazlası olarak görülen servis atma performansına etkisini araştırmak güncel çalışmaların konusu olmaktadır. Bu çalışmada, Türkiye Üniversiteler Federasyonu Ünilig Voleybol Müsabakalarına katılan sporcuların antropometrik özelliklerinin (vücut kompozisyonu, boy uzunluğu, vücut ağırlığı ve erişme yükseklikleri) kullandıkları servislerin etkinliğine ve servis performanslarına olan etkilerinin incelenmesi amaçlanmıştır. 


\section{Yöntem}

Çalışmaya, Türkiye Üniversiteler Federasyonu Ünilig Voleybol Müsabakalarına katılan ve yaşları 18-27 arasında olan gönüllü sporcular dahil edilmiştir. Deneklerin boy uzunlukları ve vücut ağırlıkları ISAK (2001) tarafindan belirtilen test protokolüne uygun şekilde, Seca marka (213 model) stadiometre ve standart ağırlık ölçer (baskül) kullanılarak $1 / 10 \mathrm{~cm}$ ve $1 / 10 \mathrm{~kg}$ hassasiyet düzeyinde ölçülmüş ve kaydedilmiştir. Servis atışında kullanılan kol ile erişme yüksekliğinin ölçülmesi için, düz ve pürüzsüz bir yüzeye sabitlenen şerit metre kullanılmıştır. Bu amaçla deneklerden; servis atışında kullandıkları kollarını yukarı kaldırarak, ayak tabanlarının yerle olan teması kesilmeden, şerit metre üzerinde uzanabildikleri en yüksek noktaya uzanmaları istenmiştir. Erişme yüksekliği en yakın $\mathrm{cm}$ cinsinden kaydedilmiştir. Vücut kütle indeksi (VKI) değerleri, Quetelet tarafindan önerilen formül kullanılarak, vücut ağırlığının, boy uzunluğunun metre cinsinden değerinin karesine bölünmesiyle (Eknoyan, 2008) hesaplanmıştır. Deneklerin yaşları ve sporcu yaşları, beyanları esas alınarak kaydedilmiştir.

Şekil 1. Servis Performansı Değerlendirmesinde Kullanılan Servis Bölgeleri

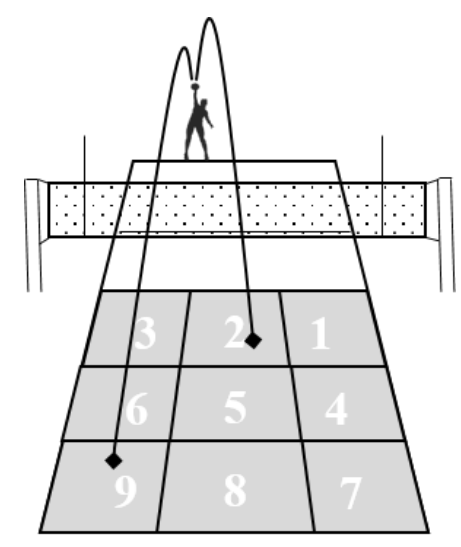

Deneklerin servis performanslarının değerlendirilmesinde, araştırmacılar tarafından geliştirilmiş olan gözlem formu kullanılmıştır. Bu formda, servis karşılayan takımın sahası ön, orta ve arka olarak 3; sol, orta ve sağ olarak da 3 olmak üzere toplam 9 eşit bölgeye $(3 \times 3 \mathrm{~m})$ bölünmüştür. Bölgelerin numaralandırılması 2 nolu pozisyondan başlayarak saat yönünün tersi istikamette 1'den 9'a kadar numaralandırılmıştır (Şekil 1). Servis atış1 yapan oyuncunun forma numarası ve servis atışı sonrasında rakip oyuncular tarafından topa ilk temas edilen bölgenin numarası kaydedilmiştir. Servis atışının rakip saha sınırları dışına düşmesi durumunda, bu durum Out" olarak belirtilmiştir. Eğer servis, servis kullanan takım lehine doğrudan sayı olarak sonuçlanmışsa Ace" olarak adlandırılmıştır. Fileye takılan servisler için File” terimi kullanılmıştır. Böylelikle, gözlem formunda her bir servis atışı için değerlendirme sonucu olarak kaydedilebilecek 12 seçenek bulunmaktadır (9 bölge, ace, out ve file). Çalı̧̧ma kapsamında 12 müsabaka gözlenmiştir. Müsabakalarda kayıt altına alınan ve çalışmaya katılmaya gönüllü olan deneklere ait 1.113 servis performansı bulunmaktadır. Çalışmanın yapılabilmesi için gerekli etik kurul izni, Hitit Üniversitesi Girişimsel Olmayan Araştırmalar Etik Kurulu'ndan (2018-63) alınmıştır. Çalışmaya katılmayı kabul eden deneklere bilgilendirilmiş gönüllü olur formu verilerek imzalamaları istenmiştir. Formu imzalamayan denekler çalışmaya dahil edilmemişlerdir.

Deneklere ilişkin tanımlayıcı istatistikler ortalama ve standart sapma şeklinde verilmiş ve servis performansı gözlem formlarından elde edilen verilerin yüzde ve frekans tabloları oluşturulmuştur. Verilerin normal dağılıma uygunluğunun test edilmesi amaciyla varyasyon katsayısı $(C V)$ ve $Q-Q$ plot grafiği değerlendirilmeleri kullanılmıştır. Verilerin normal dağılıma uygun olduğu $(C V<0,30)$ görüldüğünden (Hayran \& Hayran, 2011), servis performansının antropometrik özelliklere göre değişiklik gösterip göstermediğinin istatistiksel olarak analiz edilmesi için bağımsız örneklem $t$ testi kullanılmıştır. İstatistiksel değerlendirmelerde, anlamlılık düzeyi $p<0,05$ olarak kabul 
edilmiştir. Verilerin istatistiksel analizi SPSS (IBM Corp. 2013, Release 22.0.0.0, 64-bit edition; Lisans: Hitit Üniversitesi) paket programı kullanılarak gerçekleştirilmiştir.

\section{Bulgular}

Çalışmaya katılan sporcuların yaş, boy uzunluğu, vücut ağıllı̆̆ı, VKİ, erişme yüksekliği ve spor yaşı verilerinin tanımlayıcı istatistikleri Tablo 1'de ortalama \pm standart sapma şeklinde verilmiştir. Spor yaşı hariç olmak üzere diğer tüm değişkenlerde erkek ve kadın sporcular arasında anlamlı fark olduğu görülmüştür $(\mathrm{p}<0,01)$.

Tablo 1. Deneklere İlişkin Tanımlayıcı İstatistikler ve t Testi Sonuçları

\begin{tabular}{|c|c|c|c|c|c|}
\hline Değişkenler & Erkek $(n=65)$ & $\operatorname{Kadın}(n=47)$ & $t$ & $d f$ & $p$ \\
\hline Yaş $(y l l)$ & $21,5 \pm 1,83$ & $20,7 \pm 1,46$ & & & \\
\hline Spor yaşı (yıl) & $7,8 \pm 4,24$ & $8,1 \pm 4,29$ & & & \\
\hline Boy uzunluğu (yll) & $183,6 \pm 6,69$ & $170,2 \pm 6,90$ & 10,391 & 110 & $0.00 *$ \\
\hline Vücut a $\breve{g}$ lrlığg $(\mathrm{cm})$ & $78,8 \pm 10,57$ & $61,6 \pm 7,65$ & 9,477 & 110 & $0.00 *$ \\
\hline$V K \dot{I}\left(\mathrm{~kg} \cdot \mathrm{m}^{-2}\right)$ & $23,2 \pm 2,40$ & $21,2 \pm 2,80$ & 4,006 & 110 & $0.00^{*}$ \\
\hline Erişme yüksekliği $(\mathrm{cm})$ & $238.7 \pm 8.26$ & $213.3 \pm 10.70$ & 14,231 & 110 & $0.00 *$ \\
\hline
\end{tabular}

Tablo 2'ye bakıldığında, deneklerin servis atışlarını gerçekleştirdikleri bölgelere ve servis atışlarının başarı durumlarına göre dağılımı görülmektedir. Bu tabloya göre, 5 ve 8 numaralı bölgelerin, hem erkekler hem de kadınlar için, servis atışında en fazla tercih edilen bölgeler olduğu görülmektedir. Beş numaralı bölgeye (orta bölgenin ortası) atılan servis oranı erkeklerde \%28,5 (f=193) ve kadınlarda \%29,9 (f=130)'dur. Sekiz numaralı bölgeye (arka bölgenin ortas1) atılan servis oranı erkeklerde \%18,9 (f=128) ve kadınlarda \%20,0 (f=87)'dir. Erkeklerde en az servis atışının yapıldığı bölgeler file önü (1, 2 ve 3 nolu bölgeler) olarak görülmüştür. Bu bölgelere yapılan servis atış sayısı toplam 5 ve oranı ise \%0,7 civarındadır. Kadınlarda file önüne yapılan servis atışları, erkeklerin atışlarından daha yüksektir $(f=16 ; \% 3,7)$. Ancak erkeklerde, bu bölgeye yapılan 5 servis atışından 3 tanesi $(\% 60,0)$ doğrudan sayı (ace) ile sonuçlanırken, kadınlarda yalnızca 1 atışın $(\% 6,3)$ doğrudan sayıya neden olduğu anlaşılmaktadır. Erkeklerin kullandıkları servis atışlarının \%13,8'i $(f=94)$ hata ile (file ve out) sonuçlanırken, \%7,7'si $(f=52)$ doğrudan sayıya neden olmuştur. Kadınlarda hata oranı \%17,7 $(f=77)$ olurken, doğrudan sayı alınmasını sağlayan servis oran $1 \% 9,2(f=40)$ 'dir.

Orta bölgeye atılan (4, 5 ve 6 nolu bölgeler) servislerin oranı erkeklerde $\% 48,3$ iken $(f=327)$, bu oran kadınlarda $\% 44,4$ düzeyindedir $(f=193)$. Orta bölgeye atılan servislerde doğrudan sayı yapma oranı erkeklerde $\% 6,7(f=22)$, kadınlarda ise \%7,3 $(f=14)^{\prime}$ tür. Arka bölgeye yapılan servis atışlarına bakıldı̆̆ında, erkeklerin attıkları servislerin $\% 37,2$ 'sinin $(f=252)$ bu bölgeye atıldığ 1 , kadınlarda ise bu oranın \%34,2 $(f=149)$ olduğu görülmektedir. Arka bölgeye yapılan servis atı̧̧larında erkeklerin doğrudan sayı yapma \%10,7 (f=27), kadınların ise \%16,8 $(f=25)$ olduğu anlaşılmaktadır (Tablo 2). 
Tablo 2. Servis Atışlarının Bölgelere Göre Frekans ve Yüzde Oranları

\begin{tabular}{cccccccccc}
\hline & & \multicolumn{3}{c}{ Erkek $(\mathrm{n}=678)$} & \multicolumn{5}{c}{ Kadın $(\mathrm{n}=435)$} \\
Bölge & Alan & $\mathrm{f}$ & $\%$ & $\mathrm{f}$ & $\%$ & $\mathrm{f}$ & $\%$ & $\mathrm{f}$ & $\%$ \\
\hline \multirow{3}{*}{ Ön } & 1 & - & - & - & - & 6 & 1,4 & 1 & 2,5 \\
& 2 & 2 & 0,3 & 1 & 1,9 & 7 & 1,6 & - & - \\
& 3 & 3 & 0,4 & 2 & 3,8 & 3 & 0,7 & - & - \\
& 4 & 44 & 6,5 & 1 & 1,9 & 20 & 4,6 & 1 & 2,5 \\
Orta & 5 & 193 & 28,5 & 17 & 32,7 & 130 & 29,9 & 9 & 22,5 \\
& 6 & 90 & 13,3 & 4 & 7,7 & 43 & 9,9 & 4 & 10,0 \\
& 7 & 40 & 5,9 & 2 & 3,8 & 31 & 7,1 & 2 & 5,0 \\
\multirow{4}{*}{ Arka } & 8 & 128 & 18,9 & 14 & 26,9 & 87 & 20,0 & 15 & 37,5 \\
& 9 & 84 & 12,4 & 11 & 21,2 & 31 & 7,1 & 8 & 20,0 \\
\hline \multirow{6}{*}{} & File & 49 & 7,2 & - & - & 30 & 6,9 & - & - \\
& Out & 45 & 6,6 & - & - & 47 & 10,8 & - & - \\
& Toplam & 678 & 100 & 52 & 100 & 435 & 100 & 40 & 100 \\
\hline
\end{tabular}

*Ace saylları bölgelere atılan servis sayılarına dahildir.

Erkek ve kadın sporcuların servis başarıları arasında fark olup olmadığı bağımsız örneklem $t$ testi ile incelenmiş, servis başarısında cinsiyete göre fark olmadığı $[t(1111)=-1,733 ; p=0,713]$ görülmüştür. Antropometrik özelliklerin servis başarısına etkisine ilişkin Tablo 3'te verilen değerler incelendiğinde, erkek ve kadın sporcularda antropometrik özelliklerin servis başarısını istatistiksel olarak anlamlı düzeyde etkilemediği $(p>0,05)$ görülmektedir. İstatistiksel olarak anlamlı fark görülmemiş olmasına karşın, başarısız servis atışı gerçekleştiren erkek deneklerin boy uzunluğu ve erişme yüksekliği değerlerinin, başarılı servis kullanan deneklerin değerlerinden daha düşük olduğu anlaşılmaktadır.

Tablo 3. Antropometrik Özelliklerin Servis Başarısına Etkisi

\begin{tabular}{|c|c|c|c|c|c|c|c|c|c|c|}
\hline & & \multicolumn{3}{|c|}{ Başarılı } & \multicolumn{3}{|c|}{ Başarısız } & \multicolumn{3}{|c|}{ Bağımsız örneklem } \\
\hline & & $\mathrm{n}$ & Ort & Ss & $\mathrm{n}$ & Ort & Ss & $\mathrm{t}$ & df & $\mathrm{p}$ \\
\hline \multirow{4}{*}{ Erkek } & Boy uzunluğu $(\mathrm{cm})$ & \multirow{4}{*}{584} & 184,2 & 6,83 & \multirow{4}{*}{94} & 184,7 & 6,98 & $-0,732$ & \multirow{4}{*}{676} & 0,47 \\
\hline & Vücut ăğlrlı̆̆l (kg) & & 78,9 & 10,42 & & 79,7 & 11,74 & 0,688 & & 0,49 \\
\hline & Erişme yüksekliği $(\mathrm{cm})$ & & 230,4 & 8,35 & & 239,6 & 8,40 & 0,188 & & 0,85 \\
\hline & $V K \dot{I}\left(\mathrm{~kg} \cdot \mathrm{m}^{-2}\right)$ & & 23,2 & 2,27 & & 23,3 & 2,55 & 0,269 & & 0,20 \\
\hline \multirow{4}{*}{ Kadın } & Boy uzunluğu $(\mathrm{cm})$ & \multirow{4}{*}{358} & 170,7 & 6,63 & \multirow{4}{*}{77} & 169,7 & 6,66 & 1,210 & \multirow{4}{*}{433} & 0,23 \\
\hline & Vücut ăğlrlı̆ğ (kg) & & 62,8 & 7,05 & & 62,5 & 6,96 & 0,269 & & 0,79 \\
\hline & Erişme yüksekliği $(\mathrm{cm})$ & & 214,2 & 10,22 & & 212,0 & 10,07 & 1,769 & & 0,07 \\
\hline & $V K \dot{I}\left(\mathrm{~kg} \cdot \mathrm{m}^{-2}\right)$ & & 21,6 & 2,37 & & 21,7 & 2,45 & 0,577 & & 0,50 \\
\hline
\end{tabular}

Servis atışında doğrudan sayı alma başarısına antropometrik özelliklerin etkisinin ne olduğuna ilişkin, Tablo 4'te verilen değerler incelendiğinde, kadın deneklerde antropometrik özelliklerin servis atışında doğrudan sayı elde etme başarısını istatistiksel olarak anlamlı düzeyde etkilemediği $(p>0,05)$ görülmektedir. Ancak, erkek deneklerin boy uzunluğu ve erişme yüksekliği değişkenlerinde doğrudan sayı alma başarısında istatistiksel olarak anlamlı bir farkın olduğu $(p<0,05)$ ortaya çıkmıştır. Doğrudan sayı alma başarısını gösteren servis atışlarını yapan erkek deneklerin boy uzunluğu ve erişme yüksekliği değerlerinin sirasıyla $186,5 \pm 7,81 \mathrm{~cm}$ ve $242,3 \pm 9,70 \mathrm{~cm}$ olduğu; doğrudan say1 alma başarısını göstermeyen servis atışlarını yapan erkek deneklerin boy uzunluğu ve erişme yüksekliği değerlerinin 
ise sırasıyla $182,3 \pm 6,74 \mathrm{~cm}$ ve $239,2 \pm 8,18 \mathrm{~cm}$ olduğu görülmüştür. Erkek sporcuların doğrudan sayı başarıları üzerinde, vücut ağırlığı ve VKİ değerlerinin istatistiksel olarak anlamlı bir fark yaratmadığı tespit edilmiştir.

Tablo 4. Antropometrik Özelliklerin Servis Atışından Doğrudan Sayı Başarısına Etkisi

\begin{tabular}{|c|c|c|c|c|c|c|c|c|c|c|}
\hline & & \multicolumn{3}{|c|}{ Doğrudan sayı } & \multicolumn{3}{|c|}{ Doğrudan sayı değil } & \multicolumn{3}{|c|}{ Bağımsız örneklem } \\
\hline & & $\mathrm{n}$ & Ort & Ss & $\mathrm{n}$ & Ort & Ss & $\mathrm{t}$ & df & $\mathrm{p}$ \\
\hline \multirow{4}{*}{ Erkek } & Boy uzunluğu (cm) & \multirow{4}{*}{52} & 186,5 & 7,81 & \multirow{4}{*}{626} & 182,3 & 6,74 & 2,490 & \multirow{4}{*}{676} & $0,01 *$ \\
\hline & Vücut ă̆grliğl (kg) & & 81,1 & 11,21 & & 78,9 & 10,50 & 1,447 & & 0,15 \\
\hline & Erişme yüksekliği $(\mathrm{cm})$ & & 242,3 & 9,70 & & 239,2 & 8,18 & 2,570 & & 0,03 \\
\hline & $V K \dot{I}\left(\mathrm{~kg} \cdot \mathrm{m}^{-2}\right)$ & & 23,3 & 2,37 & & 23,2 & 2,31 & 0,111 & & 0,91 \\
\hline \multirow{4}{*}{ Kadın } & Boy uzunluğu (cm) & \multirow{4}{*}{40} & 170,3 & 6,16 & \multirow{4}{*}{395} & 170,6 & 6,69 & $-0,208$ & \multirow{4}{*}{433} & 0,85 \\
\hline & 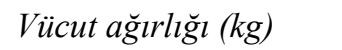 & & 62,6 & 6,00 & & 62,7 & 7,13 & 0,111 & & 0,91 \\
\hline & Erişme yüksekliği $(\mathrm{cm})$ & & 214,3 & 8,73 & & 213,8 & 10,30 & 1,266 & & 0,79 \\
\hline & $V K \dot{I}\left(\mathrm{~kg} \cdot \mathrm{m}^{-2}\right)$ & & 21,6 & 2,36 & & 21,6 & 2,39 & 0,134 & & 0,89 \\
\hline
\end{tabular}

\section{Tartışma ve Sonuç}

Günümüz voleybolunda servis, daha taktiksel bir eylem haline gelmiştir. Oyuncular servis atma tercihlerini servisi karşılayan sporculardan daha uzak noktalara atmak için özel çaba harcamaktadırlar (Arias, Rabaz, FernandezEcheverria, Dominguez, \& Arroyo, 2010). Bu çalı̧̧madan elde edilen bulgulara göre, voleybol müsabakalarında atılan servislerin çok büyük bir bölümü orta ve arka bölgeye atılmıştır. Erkekler müsabakalarında kullanılan servislerin, ön bölgeye atılması halinde doğrudan sayı yapma oranının yüksek olduğu bulunmuştur. Ancak kadınlarda, ön bölgeye atılan servislerde doğrudan sayı alma ihtimali çok düşüktür. Bunun sebebinin, erkek oyuncuların etkili servis kullanabilmek için güçlü bir şekilde vuruş yapıyor olmaları nedeniyle topun orta ve arka bölgeye düşme eğiliminin fazla olması ve rakip oyuncuların da bu duruma hazır olmak için ön bölgeyi boş bırakarak daha iyi top karşılayabilmek için orta bölgenin gerisinde ve arka bölgede hazır beklemeleri olduğu değerlendirilmektedir. Kadın oyuncuların ön bölgeye yaptıkları servis atışlarından yalnızca 1 tanesi doğrudan sayı ile sonuçlanmıştır. Bunun, kadın oyuncuların saha üzerindeki servis karşılama pozisyonlarının, erkeklerin dizilişinden farklı olması ve ön bölgeyi kontrolleri altında tutmak üzere pozisyon almış olmaları nedeniyle gerçekleştiği düşünülmektedir.

Servis başarısına servis kullanma tekniği de etki etmektedir. İtalya birinci liginde 772 servisin incelendiği çalışmada, sıçrayarak kullanılan servislerin \%69,9 oranında tercih edildiği ve bu servisin diğer servislere göre \%7,9 oranında daha başarılı olduğu gözlenmiştir (Ciuffarella vd., 2013). Başka bir çalışmada sıçrayarak kullanılan servislerin ilk set süresince en sık kullanılan servis olduğu, üçüncü set süresince ise en az kullanılan servis olduğu sonucuna ulaşılmışıı. Ayrıca oyuncular, setin sonuna yaklaştıkça, garantisi servis olarak görülen sıçrayarak atılan yüzen servisleri tercih etmektedir (Jimenez-Olmedo, Penichet-Tomas, Saiz-Colomina, Martinez-Carbonell, \& Jove-Tossi, 2013).

Servis başarıları incelendiğinde, kadınların servis başarılarının erkeklerden daha kötü olduğu görülmüştür. Erkeklerin hem boy uzunluklarının hem de erişme yüksekliklerinin kadınlardan daha iyi olduğu, ancak erkeklerin boy ve erişme yükseklikleri arttıkça başarısız servis atma ihtimallerinin arttığı, kadınlarda ise tam tersine, boy ve erişme yüksekliği azaldıkça başarısız servis atma olasılığının arttığı görülmektedir. Koley, Singh ve Sandhu (2010), yaptıkları çalı̧̧mada erkek voleybol oyuncularının, kadın voleybolculara göre daha uzun $(\% 6,63)$ ve daha ağır $(\% 7,31)$ olduğu sonucuna ulaşmıştır. Erkeklerde boy uzunluğunun artmasının, etkili servis kullanabilmek için güçlü ancak riskli servis atma eğiliminin artmış olabileceği nedeniyle gerçekleştiği düşünülmektedir. Kadınların ise, boy uzunluğu ve erişme yüksekliği azaldıkça, garanti servis atabilmek için daha garantili servis kullanma davranışına yöneliyor olabilecekleri düşünülmektedir. Pocek ve Vukovic (2013), boy uzunluğu ve vücut ağırlığının voleybol 
oyuncularının özel motor becerileri üzerinde etkilerinin olduğu sonucuna ulaşmışlar ve iskelet yapısının uzun olmasının, voleybol topuna en yüksek noktada ulaşmak için avantaj olduğunu belirtmiş̧lerdir. Mevcut çalışmadan elde edilen sonuçlar ile literatür bilgileri karşılaştıııldığında, erkeklerde boy uzunluğunun artmasının, etkin servis kullanmakta etkili olduğu düşünülmektedir. Servis atışında doğrudan sayı alma başarısı incelendiğinde, erkeklerde boy uzunluğu ve erişme yüksekliğinin bu başarıyı istatistiksel olarak anlamlı şekilde etkilediği görülmektedir. Erkek voleybolcuların boy uzunlukları ve erişme yükseklikleri arttıkça, servis atışında doğrudan sayı alma başarıları da artmaktadır. Voleybol sporunda boy uzunluğunun başarıyı etkileyen önemli bir antropometrik özellik olduğu ve müsabakalarda başarı elde edebilmek için uzun boylu oyunculara mutlak şekilde ihtiyaç duyulduğu belirtilmiştir (Tsunawake vd., 2003).

Ölçülen antropometrik özelliklerin hiç birinin, kadın deneklerin servis atışında doğrudan sayı alma başarılarına istatistiksel olarak anlamlı etki etmediği bulunmuştur. Bunun nedeninin erkeklerin daha kuvvetli ve etkili servis atışı yapabilecek fiziksel avantajlara sahip olması olduğu düşünülmektedir. Voleybol oyununda servis başarısı antropometrik özelliklerin yanı sıra kullanılan servis tekniği, oyuncuların teknik becerileri ve esneklik özelliklerine göre değişim göstermektedir. Voleybolda hücumun temposu ve türü ile blok sayısı etkin bir sayı kazanmak için önemli etkenlerdir birisidir (Castro, Souza, \& Mesquita, 2011).

Servis başarısını etkileyen birçok faktör bulunmakla birlikte, bunlardan bir tanesi de esneklik özelliğidir. Esneklik özelliğinin servis üzerine etkisinin araştırıldığı bir çalışmada, altı haftalık pilates çalışması sayesinde voleybolcuların esneklik düzeylerinde meydana gelen gelişimin servis kullanma becerisinde anlamlı bir iyileşmeye neden olduğu bilinmektedir (Manshouri, Rahnama \& Khorzoghi, 2014). Voleybol oyuncuların savunma ve blok olarak oynadıkları pozisyonlarına göre kullandıkları servislerin etkinliklerinin incelendiği bir çalışmada; hücumda etkili olmanın teknik ve yaş ile ilişkili olduğu, ancak oyuncunun saha içerisindeki görev pozisyonundan bağımsız olduğu sonucuna ulaşılmıştır (Medeiros, Mesquita, Marcelino, \& Palao, 2014). Marcelino, Sampaio ve Mesquita (2012), voleybol müsabakasında periyotlara göre kullanılan servislerin etkinliklerini inceledikleri çalışmalarında, özellikle set sonlarında kullanılan servislerin müsabaka sonucuna olan etkisine dikkat çekmişlerdir.

Erkek voleybolcuların boy uzunluğu ve erişme yüksekliklerindeki artışın servis atışının rakip sahaya gönderilmesi becerisinde istatistiksel olarak anlamlı bir etkiye sahip olmadığı, ancak bu özelliklerin, servis atışında doğrudan sayı yapmayı etkileyen antropometrik özellikler olduğu bulunmuştur. (Valleser vd., 2018), Filipinli kadın voleybolcuların antropometrik özelliklerini inceledikleri çalışmalarında, kadın voleybolcuların ortalama bir endomorf-mezomorf somatotipi ile atletik vücut yağ yüzdesi aralığında oldukları sonucuna ulaşmışlardır. Milic vd. (2018) pozisyonlarına göre başarılı oyuncuları inceledikleri çalışmalarında, başarılı oyuncuların başarısız oyunculara göre daha düşük vücut kitle indeksine sahip oldukları ve daha az mesomorfik ve daha fazla ektomorfik nitelikte oldukları sonucuna ulaşmışlardır. Ancak bu çalışmada kadın voleybolcuların antropometrik özelliklerinin voleybolda servis performansında anlamlı bir farka neden olmadığı bulunmuştur.

VKİ'nin voleybol oyuncularının performanslarına etkisi olduğunu gösteren çalışmalar bulunmaktadır (Palao, Gutierrez, \& Frideres, 2008; Gonzalez-Rave, Arija \& Clemente-Suarez, 2011). VKİ'ndeki artışın sportif performansa olumsuz etki ettiği gösterilmiştir (Mala, Maly, Zahalka, \& Bunc, 2010). Mielgo-Ayuso ve arkadaşları tarafından yapılan bir çalışmada, elit kadın voleybol oyuncularının fiziksel performanslarına antropometrik özelliklerinin etkisi incelenmiş ve VKİ ile dikey sıçrama, smaç sıçraması, omuz çemberi kuvveti arasında istatistiksel olarak anlamlı bir korelasyonun varlığı ortaya konmuştur (Mielgo-Ayuso, Calleja-Gonzalez, ClementeSuarez \& Zourdos, 2015). VKİ artışının, özellikle sıçrama özelliğine olumsuz etki edecek olması nedeniyle, oyuncular için dezavantaj yaratacağı belirtilmiştir (Bandyopadhyay, 2007). Bu çalışmada, ne erkek ne de kadın voleybolcularda VKİnin, servis başarısına istatistiksel olarak anlamlı bir etkisinin olmadığı görülmüştür. 


\section{Öneriler}

Erkek voleybolcuların boy uzunluğu ve erişme yüksekliklerinin servis performansını etkilediği belirlenen bu çalışma sonuçlarına göre, kısa boylu voleybolcuların ekstra servis atışı çalışması yapmalarının, takımların genel servis başarı yüzdelerinin yükseltebileceği değerlendirilmektedir. Kadın voleybolcularda ise servis hatasının, takımların sayı kaybetmelerindeki önemi göz önüne alındığında kadın oyuncuların servis atışlarını iyileştirmeye dayalı çalışmalar yapması önerilmektedir. Bundan sonra yapılacak olan benzer çalışmalarda, servis atış şeklinin gözlenmesi de araştırma kapsamına dahil edilebilir.

\section{Kaynakça}

Arias, A. G., Rabaz, F. C., Fernandez-Echeverria, C., Dominguez, M. A. \& Arroyo, M. P. M. (2010). Comparative Analysis of the Serve in Volleyball Between the Spanish Championships 2005-2010. Revista Internacional de Medicina y Ciencias de la Actividad Fisica y el Deporte. 16(63), 439-456.

Bandyopadhyay, A. (2007). Anthropometry and Body Composition in Soccer and Volleyball Players in West Bengal, India. Journal of Physiological Anthropology. 26(4), 501-505.

Bayraktar, B. \& Sunay, H. (2007). Türkiye'de Elit Bayan ve Erkek Voleybolcuların Spora Başlamasına Etki Eden Unsurlar ve Spordan Beklentileri. Spormetre Beden Eğitimi ve Spor Bilimleri Dergisi. 5(2), 63-72.

Castro, J., Souza, A. \& Mesquita, I. (2011). Attack Efficacy in Volleyball: Elite Male Teams. Perceptual and Motor Skills. 113(2), 395-408.

Ciuffarella, A., Russo, L., Masedu, F., Valenti, M., Izzo, R. E. \& De Angelis, M. (2013). Notational Analysis of the Volleyball Serve. Timisoara Physical Education and Rehabilitation Journal. 6(11), 29-36.

Çon, M., Akyol, P., Tural, E. \& Taşmektepligil, M.Y. (2012). Voleybolcuların Esneklik ve Vücut Yağ Yüzdesi Değerlerinin Dikey Sıçrama Performansına Etkisi. Selçuk Üniversitesi Beden Eğitimi ve Spor Bilim Dergisi. 14(2), 202-207.

Dinçer, Ö. (2016). Voleybolda Kullanılan Kısa ve Uzun Servis Tekniğini Yüzeyel EMG ile İncelenmesi. Uluslararası Anadolu Spor Bilimleri Dergisi. 1(1), 85-90.

Eknoyan, G. (2008). Adolphe Quetelet (1796-1874): The Average Man and Indices of Obesity. Nephrology Dialysis Transplantation. 23, 47-51.

Gonzalez-Rave, J. M., Arija, A. \& Clemente-Suarez, V. (2011). Seasonal Changes in Jump Performance and Body Composition in Women Volleyball Players. Journal of Strength and Conditioning Research. 25, 1492501.

Göral, K., Saygın, Ö., Karacabey, \& K., Gelen, E. (2009). Tenisçiler ile Voleybolcuların Bazı Fiziksel Uygunluk Özelliklerinin Karşılaştırılması. e-Journal of New World Sciences Academy. 4(3):227-235.

Hayran, M. \& Hayran, M. (2011). Sağlık Araştırmaları İçin Temel İstatistik. Art Ofset Matbaacılık. Ankara.

International Standards for Anthropometric Assessment (2001). International Society for the Advancement of Kinanthropometry (ISAK). Avustralya.

İlhan, L. (2009). Voleybolda Servis Becerisi Öğretimine Motivasyonel Bir Yaklaşım. Niğde Üniversitesi Beden Eğitimi ve Spor Bilimleri Dergisi. 3(3), 196-203.

Jimenez-Olmedo, J. M., Penichet-Tomas, A., Saiz-Colomina, S., Martinez-Carbonell, J. A. \& Jove-Tossi, M. A. (2012) Serve analysis of professional players in beach volleyball. Journal of Human Sport and Exercise. 7(3), 706-713.

Kamuk, Y. U. (2009). Antropometrik Özelliklerin Mini Voleybolcuların Servis Performanslarına Etkileri. Beden Eğitimi ve Spor Araştırmaları Dergisi. 9(1), 1-12.

Koley, S., Singh, J. \& Sandhu, J. S. (2010) Anthropometric and Physiological Characteristics on Indian Interuniversity Volleyball Players. Journal of Human Sport and Exercise. 5(3), 389-399

Kürkçü, R., Hazar, F. \& Özdağ, S. (2009). Futbolcuların Vücut Kompozisyonu, Vücut Bileşenleri ve Somatotip Özellikleri Üzerine Bir İnceleme. Niğde Üniversitesi Beden Ĕgitimi ve Spor Bilimleri Dergisi. 3(2), 113-119. 
Lale, B., Müniroğlu, S., Çoruh, E. \& Sunay, H. (2003). Türk Erkek Voleybol Milli Takımının Somatotip Özelliklerinin İncelenmesi. Spormetre Beden Eğitimi ve Spor Bilimleri Dergisi. 1(1), 53-56.

Mala, L., Maly, T., Zahalka, F. \& Bunc, V. (2010). The Profile and Comparison of Body Composition of Female Volleyball Players". Kinesiology. 42, 90-97.

Manshouri, M., Rahnama, N. \& Khorzoghi, M. B. (2014). Effects of Pilates Exercises on Flexibility and Volleyball Serve Skill in Female College Students. International Journal of Current Research. 6(12), 1118811192.

Marcelino, R. O., Sampaio, J. E. \& Mesquita, I. M. (2012) Attack and Serve Performances According to the Match Period and Quality of Opposition in Elite Volleyball Matches. Journal of Strength and Conditioning Research. 26(12):3385-3391.

Medeiros, A. I. A., Mesquita, M. I., Marcelino, O. R. \& Palao, J. M. (2014). Effects of Technique, Age and Player's Role on Serve and Attack Efficacy in High Level Beach Volleyball Players". International Journal of Performance Analysis in Sport, 14(3), 680-691.

Mielgo-Ayuso, J., Calleja-Gonzalez, J., Clemente-Suárez, V. J. \& Zourdos, M. C. (2015). Influence of Anthropometric Profile on Physical Performance in Elite Female Volleyballers in Relation to Playing Position". Nutricion Hospitalaria. 31(2), 849-857.

Milic, M., Grgantov, Z., Chamari, K., Ardigo, L. P., Bianco, A. \& Padulo, J. (2017) Anthropometric and Physical Characteristics Allow Differentiation of Young Female Volleyball Players According to Playing Position and Level of Expertise". Biology of Sport. 34(1), 19-26

Palao, J. M., Gutierrez, D. \& Frideres, J. E. (2008). Height, Weight, Body Mass Index, and Age in Beach Volleyball Players in Relation to Level and Position. Journal of Sports Medicine and Physical Fitness. 48(4), 46671

Palao, J. M., Manzanares, P. \& Valades, D. (2014). Anthropometric, Physical, and Age Differences by the Player Position and the Performance Level in Volleyball. Journal of Human Kinetics. 44, 223-36

Pastuszak, A., Busko, K. \& Kalka, E. (2016) Somatotype and body composition of volleyball players and untrained female students - reference group for comparison in sport. Anthropological Review, 79(4), 461-470

Patsiouras, A., Moustakidis, A., Charitonidis, K. \& Kokaridas, D. (2011). Technical Skills Leading in Winning or Losing Volleyball Matches During Beijing Olympic Games. Journal of Physical Education and Sport. 11(2), 149-152

Paulo, A., Zaal, F.T.J.M., Fonseca, S. \& Araujo, D. (2016) Predicting Volleyball Serve-Reception. Frontiers in Psychology. 7:1694, 1-9. doi: 10.3389/fpsyg.2016.01694

Pena, J., Rodriguez-Guerra, J., Busca, B. \& Serra, N. (2013). Which Skills and Factors Better Predict Winning and Losing in High-Level Men's Volleyball?. Journal of Strength and Conditioning Research. 27(9), 24872493

Pocek, S. \& Vukovic, M. (2013). Impact of Body Height and Weight on Specific Motor Abilities of Volleyball Players". Obtained from: https://www.academia.edu/3297230/impact_of_ body _height_and_weight_on_specific_motor_abilities_of_volleyball_players on January 5, 2019

Silva, M., Lacerda, D. \& Joao, P. (2014). Game-Related Volleyball Skills that Influence Victory. Journal of Human Kinetics. 41, 173-179

Stamm, R., Veldre, G., Stamm, M., Thomson, M., Kaarma, H., Loko, J. \& Koskel, S. (2003) Dependence of Young Female Volleyballers' Performance on Their Body Build, Physical Abilities, and Psycho-Physiological Properties. The Journal of Sports Medicine and Physical Fitness. 43, 1-9

Şimşek, B., Tuncel, F., Ertan, H. \& Göktepe, S. (2005). Farklı Lig Kategorilerindeki Bayan Voleybol Oyuncularının Seçilmiş Fiziksel Uygunluk Parametrelerinin Değerlendirilmesi”. Gazi Beden Eğitimi ve Spor Bilimleri. 10(3), 29-38 
Tsunawake, N., Tahara, Y., Moji, K., Muraki, S., Minowa, K. \& Yukawa, K. (2003) Body Composition and Physical Fitness of Female Volleyball and Basketball Players of The Japan Inter-High School Championship Teams. Journal of Physiological Anthropology and Applied Human Science. 22(4), 195201

Valleser, C. W. M., Bersola, K. A. R., Mallari, M. F. T., Papa, E. L. V., Diaz, F. C. B., Maghanoy, M. L. A. \& Lariosa, C. J. D. (2018). Anthropometric Profile of Elite Women's Volleyball Players in the Philippines. Turkish Journal of Kinesiology. 4(2), 53-57 